\title{
Digital intelligence of a modern economist: an exploratory case study
}

\author{
Olena Glazunova ${ }^{1, *}$, Taisiia Saiapina ${ }^{1,}$, Valentyna Korolchuk $^{1,}$, Olga Kasatkina ${ }^{1,}$, and Tetiana Voloshyna $^{1,}$ \\ ${ }^{1}$ National University of Life and Environmental Sciences of Ukraine, 15 Heroiv Oborony Str., Kyiv, 03041, Ukraine
}

\begin{abstract}
In the current context of digitalization of various spheres of life, an important characteristic of participants in a digital society is the level of their digital intelligence. The level at which future economists develop their digital intelligence skills during university depends on their successful employment and career development. The presented article analyses the concept of digital intelligence of an economist on the basis of the Digital Quotient framework developed by the Digital Intelligence Institute, characterizing the levels of "Digital Citizen", "Digital Creator", "Digital Entrepreneur" for such components of digital intelligence as: Digital Changemaker Identity, Digital Use, Safety Digital, Digital Security, Digital Emotional Intelligence, Digital Communication, Digital Literacy, Digital Rights. For the first time, the contents of an academic discipline of a university training programme for future economists have been proposed, in the course of which digital intelligence skills can be developed. The authors demonstrate the stages of formation, indicators for different levels of formation, content and examples of educational representation of material. They offer the stages of Digital intelligence development in the framework of studying the course modules, the implementation of project work and the solution of the real case studies during academic training. The results of the pilot study for achieving all three levels of digital intelligence. A statistical analysis of the results of the experiment was carried out and their relevance proved.
\end{abstract}

\section{Introduction}

The modern economy requires the digitization of economic processes, which is the basis of innovative development of economic systems. Digital economy is creating new products, shaping new needs, and the speed and volume of information is increasing day by day. The development of digital intelligence among economic actors offers significant opportunities to create and conduct business based on new technological solutions or business models not previously applied. At the current stage of the development of the global economy, digital tools were accompanying all aspects of economic activity, and digital data technology and e-business were receiving increasing attention.

The use of digital technologies is transforming the relations between the participants of economic activity in its various sectors. That is why the formation and development of digital competences in economists, both general and professional, is an important task for modern universities in preparing future economists and improving their skills. International and European institutions pay great attention to the development of standards of digital competence, in particular, the framework of digital intelligence provides the ability to adequately use digital technologies to work with data, management information systems, economic risks, provide cybersecurity, digital communication and more. The development of such abilities among future economists needs to take place both during the train-

*e-mail: o-glazunova@nubip.edu.ua ing of information technology disciplines and in professionally oriented (vocational) academic disciplines. It is therefore necessary to develop the content, methods and forms for the formation and development of digital intelligence skills of future economists during university studies through appropriate educational programs.

Digital skills are one of the most important conditions for the development of the digital market in any country, as they are directly or indirectly linked to all spheres of society and the economy. Significant work has been done by the European community to create the potential for digital transformation of education, in particular, to change the skills and competences requirements for citizens. The work was focused on developing a digital competency framework for citizens (DigComp), educators (DigCompEdu), educational organizations (DigCompOrg) and consumers (DigCompConsumers). Digital competences, computer skills, information literacy and related abilities represent a crucial element in ICT education (Information and Communication Technologies) [1]. Digital competence is a basic skill for citizens and should be systematically assessed, taking into account characteristics such as knowledge, skills and attitudes [2].

Any framework of digital competence presented necessarily requires mastery of the components of digital intelligence. Y. Park [3] defines digital intelligence as a set of social, emotional and cognitive abilities that allow individuals to meet challenges and adapt to the requirements of digital life. By acknowledging conceptual dyad, digital intelligence could be a result of the process of digital learn- 
ing [4]. Since digital technologies support the learning process and have become an educational subject as well as teaching content, the development of digital intelligence is encouraged in contemporary students [5].

Today's education is best met by the concept of digital intelligence development that includes eight interconnected areas: digital identity, digital use, digital safety, digital security, digital emotional intelligence, digital communication, digital literacy, and digital rights [6]. D. Cismaru, P. Gazzola, R. S. Ciochina, C. Leovaridis [7] explores the development of four categories of skills (operational, informational, strategic and digital fluency) as dimensions of the digital intelligence.

Entrepreneurs are often pressed to create and launch products and services as quickly as possible to achieve a first-mover advantage in the market. In doing so, they tend to overlook cybersecurity threats and risks due to a lack of awareness and insufficient funding. This can lead to theft of intellectual property, project failure, and inaccurate risk assessment [8].

The purpose of the article is to define the notions, components, levels and characteristics of digital intelligence of the modern economist, to develop approaches to the formation and development of components of digital intelligence of future economists in higher education.

\section{Digital intelligence of a modern economist: structure, indicators, levels}

Digital economy is based on information and communication and digital technologies, the rapid development and spread of which are already affecting the traditional (physical - analogue) economy, transforming it from a resourceconsuming economy to a resource-creating economy [911]. Data are the key resource of the digital economy, generated and enabled by electronic communications through the operation of digital devices, tools and systems. In order to achieve digital competitiveness in the digital economy, it is necessary to develop the digital intelligence skills in a future economist.

Similar to IQ and EQ, which are used to measure general and emotional intelligence, digital skills are DQ (Digital Quotient), which is digital intelligence. The DQ framework contains 3 levels of digital intelligence [12]:

- "digital citizenship" is the use of digital technologies in everyday life, for interaction with each other, communication, viewing of digital content, etc.

- "digital creativity" is the use of digital technologies to create content, media, applications, etc.

- "digital entrepreneurship" is the use of digital technologies for business, professional activity, etc.

In our study, we define digital intelligence of future economists as a combination of theoretical knowledge, practical skills and abilities that allow to respond quickly to challenges and adapt to modern requirements of the digital society. Possessing such skills will enable future economists to adequately use digital tools for data retrieval and processing, apply management information systems, manage economic risks, provide cybersecurity measures and establish mass digital communication in today's online space. The defined levels are applied to such components of digital intelligence as: Digital Changemaker Identity, Digital Use, Digital Safety, Digital Security, Digital Emotional Intelligence, Digital Communication, Digital Literacy, Digital Rights. In order to determine indicators for all components of the future economist's digital intelligence, it is necessary not only to analyze the DQ framework, but also the labor market requirements to the competences of a modern digital economist. The description of the components of digital intelligence is presented in figure 1. Thus, two basic academic disciplines - Information Technology in Economics and Database Management Systems, in the program of training of specialists in the economy are responsible for the formation of digital skills.

According to the data of DQ Institute, a person possesses Digital Changemaker Identity if he/she knows the general and emerging trends in the digital environment, identifies and evaluates innovative opportunities for business or social impact, provided by the improvement of new technologies, development of higher-order thinking skills, expansion of thinking beyond the individual scale to integrate digital networks and tools in response to broader social and economic challenges. Such people demonstrate professionalism and value, an interest in understanding the existing gaps in their digital competence and technology, using them for self-development and further business growth [13]. At the Future of Jobs Report forum, it was stated that the more work on soft skills in addition to hard skills, the more navigate easily tomorrow's job market [14]. Soft skills are crucial for the complex and dynamic process of career management and development for an economist mostly within the knowledge-based society context [15]. Teaching detailed and nuanced industry knowledge is arguably beyond the scope of entrepreneurship education systems, but to an extent, it is of paramount importance that students are exposed to the organic industry knowledge through interaction and experiential experiences. Within such interaction, the development of convergent 21 st century skills such as social relationships, leadership, creativity and critical thinking further nurture entrepreneurial intents among students [16]. The indicator of the Digital Changemaker Identity is the ability to identify and develop yourself as a competent digital technology user in Economics. Within the framework of both academic disciplines, namely Information Systems and Technology in Economics and Database Management Systems the Digital Changemaker Identity skills can be developed through the use of project-based, case-based, and practiceoriented training.

Digital data technology, information systems in management, accounting and finance are increasingly playing a key role in managing business processes, including all areas of economic activity, and future economists therefore need Digital Use skills. In [17] several considerations and suggestions are drawn in terms of rethinking and pursuing usability in training when applied to Enterprise Resource Planning (ERP), and other business process management 


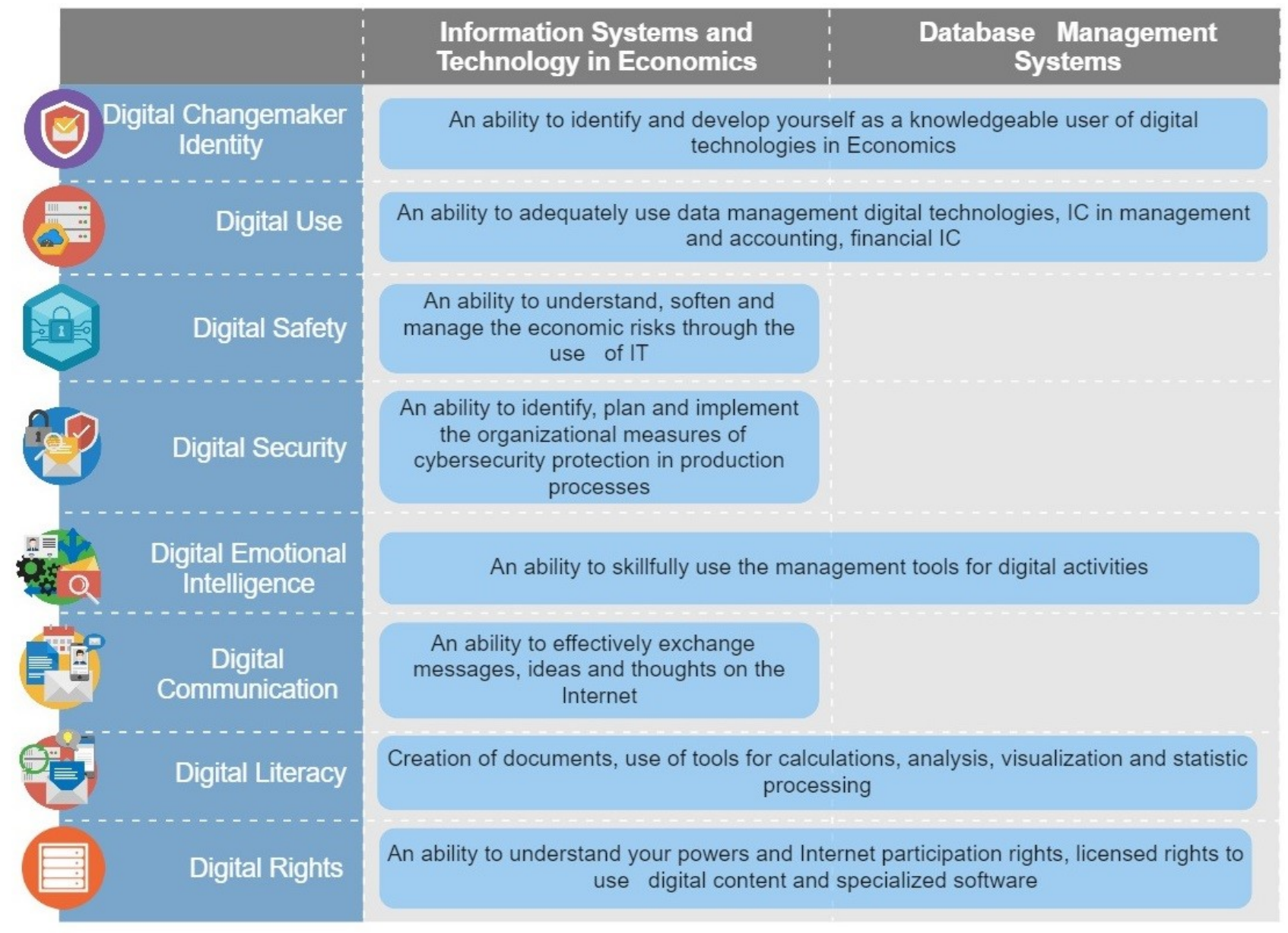

Figure 1. Components of digital intelligence

software systems, SAP, which comes as an integrated solution that incorporates the key business functions and processes of an organization. The rapid growth through the use of Enterprise Resource Planning (ERP) systems by Indonesian companies has been responded by ERP vendors in providing skilled human resources in ERP environment by cooperating with universities, particularly for training accounting students. Satisfaction with class and instructor influence perceived ease of use, students feel satisfied with ERP training and this affects their intentions in using ERP in the future [18]. In article [19] presents the enterprise resource planning (ERP) course layout aiming at the current problems from six aspects of the curriculum, teaching content, teaching resource, teaching method, teaching evaluation, teacher training. M. Shraideh, C. Drieschner, B. Betzwieser, H. Kienegger, M. Utesch, H. Krcmar [20] planning and conduct a practical course for teaching topics of SAP Leonardo and SAP HANA by suggesting model for conducting a capstone course consisting of eight phases. The model is geared to teaching new and innovative industry-related topics by using a project-based learning approach including elements of experiential learning and role-play teaching. The formation and development of such skills is ensured in the course of studying Information Systems and Technology in Economics and Database management systems academic disciplines, as well as pro- fessionally oriented disciplines in economics, accounting, analysis, modeling, management.

Organizations are faced with increasing complexity, uncertainty and enhanced threats from a wide range of forces. Depending on how this situation is handled, it can become risk or opportunity to erode or enhance business value. In addition, organizations have to meet most different stakeholders', legal and regulatory risk management requirements, comprehensive enterprise risk management are challenge and core competence for organizations' sustainable success [21]. Y. Raanan [22] research witch applications of risk management to many aspects of modern life, from insurance, banking, health issues, business ventures, to project management and more. The Digital Safety indicator is the ability to understand, mitigate and manage economic risks using IT.

Integration of digital security skills as an independent variable is critical to the understanding of the use of online protective measures. Having the necessary skills and knowledge to engage in a cyber-safety behavior can help users avoid cyber-victimization, reducing the odds of negative outcomes such as the theft of data, money or personal information [23]. Knowledge and skills in the areas of information security, information privacy, and copyright/intellectual property rights and protection are of key importance for organizational and individual success in an 
evolving society and labor market in which information is a core resource [24]. The indicators Digital Security are the ability to recognize, plan and deploy organizational cybersecurity tools in manufacturing processes. The formation of students' Digital Security level is carried out in the process of mastering the content-rich Module "Digital Security: Protection in the Digital Environment" within the framework of Information Systems and Technology in Economics course.

It is widely acknowledged that emotional intelligence is a crucial component in organizations. It has been proved that leaders and employees who are emotionally intelligent are more efficient, creative, and make better decisions [25]. In today's digital and technical environment, employers are looking for personnel that can contribute to the organization not only with the use of technical skills but can also express their expertise with the use of positive emotional intelligence and communication effectiveness [26]. The indicator of Digital Emotional Intelligence is the possibility to skillfully use digital tools for management. The formation and development of such skills are ensured in the process of studying basic academic disciplines in information technologies - namely, Database Management Systems and Information Systems and Technology in Economics, as well as professionally oriented academic disciplines in management, project management and business modeling.

The importance of Digital Communication for economists is beyond question, as information and communication technologies are a driver of the digital economy [27]. Digital communication and collaboration use features of digital technologies with confidence for communication, cooperation and collaboration; effectively search, find, retrieve, process and communicate information from a variety of digital sources and in a variety of formats [28]. The ability for an undergraduate economist to apply analytical skills to economic issues of contemporary relevance is an integral part of their tertiary training. In order to encourage students M. O'Brien and K. Freund [29] explored the potential for future economist to exploit their social media communication skills with reflective blogging. The indicator of Digital Communication is an ability to effectively exchange messages, ideas and thoughts on the Internet. The formation of appropriate skills of Digital Communication in future economists can be carried out within Information Systems and Technology in Economics academic discipline while studying the informative module "Digital Communications in Global Space". Therefore, Digital Communication for the modern economist is both the ability to use the tools of gathering and disseminating professional economic information and data, assessable through digital means. This level partly overlaps with Entrepreneurial competence and is one of the main components of Digital Competence.

Information technologies are rapidly evolving and changing, along with that the term Digital Literacy is constantly acquiring new interpretations. This means that the role of information technologies in training specialists in different areas is undergoing constant change as well [3032]. As stressed by M. Murray and J. Perez [33], many students entering the university today have a high level of exposure to digital technologies and media. However, they are not prepared to cross the bridge between personal and academic use of technology. As academic know-how is gained through formal education, so too must technological prowess be gained through structured learning experiences. B. Chan, D. Churchill and T. Chiu [34] define digital literacy as "the ability to understand and use information in multiple formats with emphasis on critical thinking". The indicator of Digital Literacy of a future economist the creation of documents, use of tools for calculations, analysis, visualization and statistic processing. Economists may achieve such a level of Digital Literacy if they possess experience of using different technologies gained not only within the framework of studying such academic disciplines as Information Systems and Technology in Economics at the university, but also in the process of professional activity.

Organizations require skilled and knowledgeable professionals who understand risks and responsibilities related to the management of information privacy, information security, and copyright/intellectual property [24]. New digital networked technologies enable users to participate in the consumption, distribution, and creation of content in ways that are revolutionary for both culture and industry. Young people operate in the digital realm overwhelmingly ignorant of the rights, and to a lesser degree the restrictions, established in copyright law [35]. Software publishers use digital rights management, specifically copy-protection techniques, to prevent unauthorized and illegal copying of their software products [36]. The indicators of Digital Rights are the ability to understand your powers and Internet participation rights, licensed rights to use digital content and specialized software.

Competency indicators have been developed for each component of digital intelligence.

Indicators of digital intelligence skills at the level of "Digital Citizen":

DigCitizen1. Digital Changemaker Identity (using digital technologies to build your own image and the impact of knowledge and technology on professional development; using technologies to control and form your own digital identity; demonstrating honesty in technology use and self-efficacy by finding ways to take advantage of the opportunities available to you in the digital environment);

DigCitizen2. Digital Use (understanding of the impact of the use of digital technologies on health, productivity of work, welfare and lifestyle, the possession of the relevant knowledge to solve these consequences; the use of technology in a targeted manner to achieve better objectives, effective use of digital content and tools for their own benefit);

DigCitizen3. Digital Safety (understand the different types of behavioural cyber risks, how he/she can face these risks, how these risks can 
affect him/her; develop the necessary technical, socio-cognitive, communicative and decision-making skills to deal with cyber risk situations when they occur; know the tools to overcome these negative outcomes on the Internet);

DigCitizen4. Digital Security (ability to recognizing and eliminate technical and software cyber threats at the level of the operating system; work in the network, with personal data and copyrighted content; know the types of threats in the digital environment, identify strategies and tools to be used to avoid such threats; use digital technologies without compromising their data and devices);

DigCitizen5. Digital Emotional Intelligence (possess social and emotional skills in digital interaction of people, connected with both psychological interaction and practical, physical actions in confirmation of socially determined socially significant things);

DigCitizen6. Digital Communication (level to know and to be able to use various communication tools for effective messaging);

DigCitizen7. Digital Literacy (ability to find, process, organize, visualize and store economic data);

DigCitizen8. Digital Rights (understand the concept of confidentiality as a human right, what personal information is and how it can be used, stored, processed and shared on digital platforms along with strategies and tools that help keep personal information private and secure; is aware of copyright licenses and Creative Commons tools, licensing choices for licensors).

Indicators of digital intelligence skills at the level of "Digital Creator":

DigCreator1. Digital Changemaker Identity (future economist's understanding of how to be aware of the progress of ICT; ability to integrate digital technologies in professional life; ability to explore and identify contemporary problems, jointly develop new ideas for their solution through technology);

DigCreator2. Digital Use (ability to develop new ideas for solving the given tasks; to use selfmotivation and ingenuity in using technologies in professional activity, for allocating available resources; select and use digital technologies and information systems to plan and execute business processes);

DigCreator3. Digital Safety (understanding the cyber risks of content they face on the Internet; understanding the strategies associated with appropriate behavior, and the skills needed to develop; using conflict management techniques to reduce cyber risks);

DigCreator4. Digital Security (ability to plan and implement cybersecurity protection in the creation of digital content, organization of data security and working information systems; identify vulnerabilities, quantify associated risks (e.g., income deficiency or business losses); use tools, strategies and protocols to ensure and improve data privacy and security);

DigCreator5. Digital Emotional Intelligence (identify, understand and use your own emotional states, to be able to direct them; promote cooperation and positive interaction between internal and external interested parties in order to achieve the set goal; understand and use your own emotional states, which are derivative and primary to digital media and personal value systems);

DigCreator6. Digital Communication (create and transmit digital content, independently organize communication channels for communications (for a large number of users inclusive); store message histories, to resume task on the needed Internet page, the ability to use multiple communication tools without disrupting the workflow; ability to creating and organize videoconferencing);

DigCreator7. Digital Literacy (ability to work with software environments for automation of processes of economic data processing (statistical, analytical); ability to create and use database management systems, data warehouses; ability to create and use economic and mathematical methods and models, diagnostic methods of control and estimation of the level of economic growth by means of automation using digital tools; ability to model and forecast economic processes using modern digital technologies);

DigCreator8. Digital Rights (knowledge of the law and rights regarding the ownership of information and content hosted in a digital environment; ability to distinguish between creative use and appropriation of someone else's work; ability to track and manage changes to your digital content to protect your/organizational assets from unauthorized changes or unauthorized use; ability to design and use patents, trademarks, copyrights to protect your digital works through a variety of tools and applicable legislation).

Indicators of digital intelligence skills at the level of "Digital Entrepreneur": 
DigEntrepreneur1. Digital Changemaker Identity (ability to identify and evaluate innovative business or social impact opportunities that are enhanced by new technologies; ability to monitor and integrate emerging trends and technologies; ability to structure data collection to identify new technology products / services that determine the potential added value of the business for sustainability and profitability of the business);

DigEntrepreneur2. Digital Use (use digital technologies to improve organizations, achieve business goals, work with economic indicators, information systems covering all spheres of economic activity, use systems to manage enterprise resources; create, implement and use information systems and technology in different spheres of economic activity);

DigEntrepreneur3. Digital Safety (understand different types of cyber risks of commercial organizations, which can cause cessation or slowdown of business processes, loss of competitive advantage, loss of customers or profit, reduction of the business value and so forth; ability to identify risks and to develop creative strategies using digital tools to address and prevent the threats associated with those risks);

DigEntrepreneur4. Digital Security (ability to organize a secure information environment for the business organization; ability to support cyber security in the organization, providing advice and guidance on potential risks and strategies for addressing them by developing and adhering to already developed communication strategies for organizations to ensure adoption and compliance of security policies and standards that ensure a viable environment for the enterprise);

DigEntrepreneur5. Digital Emotional Intelligence (ability to develop interpersonal skills; ability to manage one's emotions, understand emotional responses and behaviors depending on the context and digital environment; ability to build partnerships at personal, local, social and global levels to achieve organizational goals);

DigEntrepreneur6. Digital Communication (ability to create and establish different commu- nication environments to discuss; ability to formulate business strategies and tactics in order to achieve the organization's goals);

DigEntrepreneur7. Digital Literacy (ability of a student to design databases, information systems, algorithms and data collection tools; develop decision-making models);

DigEntrepreneur8. Digital Rights (ability to effectively integrate legislation with one's own practice to ensure the support and enforcement of digital rights in the digital environment as part of the entrepreneurial activity).

\section{Results and discussion}

The pedagogical experiment on the development of digital intelligence competences for future economists lasted for 3 years and involved the first year students majoring in Economic (the total of 142 students). The formation and development of digital intelligence skills of future economists was carried out within the framework of studying the Information Systems and Technology in Economics academic discipline. The formation of DQ was carried out in 3 stages: (1) Digital Citizenship through two content modules in the Information Systems and Technology course; (2) Digital Creativity through a competencybased project; (3) Digital Entrepreneurship through practical training using real-life work situations. The course of experimental research included measuring students' digital intelligence skills before the start of the discipline and at the end of each stage.

The course content modules on Information Systems and Technology in Economics included: Digital Identity and Rights of the Modern Economist, Digital Security: Protection in the Digital Environment, Cyber Risks in the Public Digital Domain, Digital Communications in the Information Environment, Economic Data Tools, Visualisation of Economic Information, Digital Tools for Economist Management, Information Systems for Economic Activity. The process of forming appropriate skills in accordance with the components of digital intelligence level "Digital Citizen" was provided by a set of educational resources and services, tasks for laboratory work.

After completing the two modules of the discipline, students were offered a project assignment to achieve the Digital Creativity level. During the project work, students learned how to apply a set of services and tools developed during theoretical training to solve different types of tasks related to economic activity of an enterprise. Before starting the tasks of this project, the students had to split into small groups, plan the teamwork, choose a service to manage the project, assign roles to the participants, set areas of responsibility and deadlines for the tasks. In the course of the project assignment, the students were asked to develop the information structure of the virtual business activity based on the analysed organisational and functional 
structure of the enterprise; to select the software for economic activity (processing, systematisation, visualisation and storage of economic data), tools for confidentiality and data security using appropriate cloud services.

In order to achieve the "Digital Entrepreneurship" level of the learning experience, the students were asked to solve a case study based on the production situation described. An example of such a task is given below. "A retail chain is planning to expand its branches. Given the number of employees, customers and counterparties of the company planned after the expansion, to analyse the technical and functional characteristics of the existing systems in the market and to select the optimal in terms of purchase and maintenance costs: CRM-system; tool for checking the activities of counterparties; tool for assessing the financial performance of the company. Evaluate the cost of implementing such systems in the company. Set up user authorisation rules in the selected systems to ensure the security of company data". The result of the completed task is a presentation of the completed work in the form of a joint document, which is generated by all participants of the project.

The leading idea of the research concept is reflected in the hypothesis based on the assumption: if the training of modern economists is carried out according to the proposed phased formation of digital intelligence skills, it will increase the levels of digital intelligence: "Digital Citizen", "Digital Entrepreneur" and "Digital Creator".

At the beginning of the pedagogical experiment, each student assessed their own level of competence in the components of digital intelligence in accordance with the developed indicators on a scale from 0 to 10 for the levels of "Digital Citizen", "Digital Creator", 'Digital Entrepreneur". For each level, the average value of the formation of the corresponding component of digital intelligence was determined. After completing the training, in which students were offered resources, tasks, training practices for the formation of digital intelligence skills at different levels during three stages, students were asked to re-evaluate the level of formation of digital intelligence competencies. The results of the experiment for 3 academic years on the formation of competencies in digital intelligence at the levels of "Digital Citizen", "Digital Creator", "Digital Entrepreneur" are presented in Table 1-3.

To confirm the hypothesis of the study, a null hypothesis was put forward: the average value of the level of formation of digital intelligence before and after the experiment for each level does not differ. Deviation of this hypothesis for each level will confirm the effectiveness of the technologies used. The sample data have a normal distribution and form a pair of correlating values, whereas the paired Student $t$-test was chosen to evaluate the results.

Assessment of digital intelligence skills at the level of "Digital Citizen" is presented in table 1.

The sample data have a normal distribution and form a pair of correlating values, whereas the paired Student ttest was chosen to evaluate the results. The t-criterion was calculated by the formula $t=\frac{\left|M_{d}\right|}{\frac{S_{d}}{\sqrt{N}}}$, where $M_{d}-$ is the mean difference of the values, $S_{d}$ - standard deviation, $N$ - the
Table 1. Assessment of digital intelligence skills at the level of "Digital Citizen"

\begin{tabular}{lllll}
\hline \multirow{2}{*}{$\begin{array}{l}\text { Components } \\
\text { of digital }\end{array}$} & \multicolumn{2}{l}{ Sampling } & \multicolumn{2}{l}{$\begin{array}{l}\text { Deviation from } \\
\text { the average }\end{array}$} \\
\cline { 2 - 5 } intelligence & To & After & To & After \\
\hline DigCitizen1 & 4.78 & 7.94 & 0.26 & 1.14 \\
DigCitizen2 & 3.95 & 6.33 & -0.57 & -0.47 \\
DigCitizen3 & 3.70 & 5.67 & -0.82 & -1.13 \\
DigCitizen4 & 5.69 & 7.27 & 1.17 & 0.47 \\
DigCitizen5 & 4.26 & 7.41 & -0.26 & 0.61 \\
DigCitizen6 & 3.81 & 5.27 & -0.71 & -1.53 \\
DigCitizen7 & 4.86 & 7.84 & 0.34 & 1.04 \\
DigCitizen8 & 5.13 & 6.67 & 0.61 & -0.13 \\
\hline$\sum$ & 36.18 & 54.40 & 0.02 & 0.00 \\
Average value & 4.52 & 6.80 & & \\
\hline
\end{tabular}

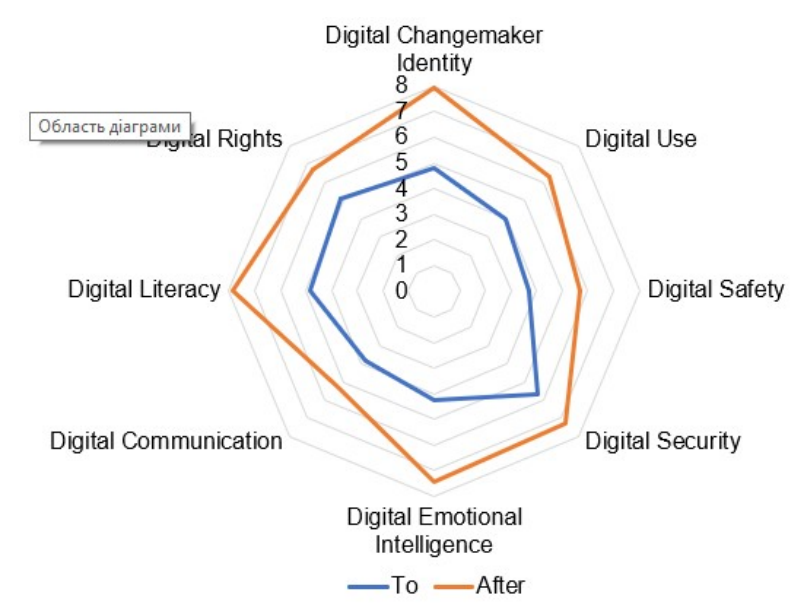

Figure 2. Graphical interpretation of digital intelligence skills at the level of "Digital Citizen"

number of parameters. The estimated t-criterion is 8.7 , the critical value of the Student's t-criterion for the number of degrees of freedom 7 is 2.365 . Since $t_{\text {estimated }}>t_{\text {critical }}$, we can reject the null hypothesis and conclude that the difference in average values before and after the experiment is statistically significant $(p=0.05)$.

As can be seen from table 1 , students have increased the level of skills "Digital Citizen" as a result of studying the proposed courses by an average on $22.8 \%$. Graphical interpretation of the results of the experiment for the level of "Digital Citizen" are given in figure 2.

Assessment of digital intelligence skills at the level of "Digital Creator" is presented in table 2.

The estimated t-criterion is 2.534 and exceeds the $t_{\text {critical }}$, we can reject the null hypothesis and conclude that the difference in average values before and after the experiment is statistically significant $(p=0.05)$.

As can be seen from table 2, students increased the level of skills of "Digital Creator" as a result of project tasks by an average of $27.3 \%$. Graphical interpretation of the results of the experiment for the level of "Digital Creator" are given in figure 3 . 
Table 2. Assessment of digital intelligence skills at the level of "Digital Creator"

\begin{tabular}{lllll}
\hline \multirow{2}{*}{$\begin{array}{l}\text { Components } \\
\text { of digital }\end{array}$} & \multicolumn{2}{l}{ Sampling } & \multicolumn{2}{l}{$\begin{array}{l}\text { Deviation from } \\
\text { the average }\end{array}$} \\
\cline { 2 - 5 } intelligence & To & After & To & After \\
\hline DigCreator1 & 2.91 & 5.35 & -0.07 & -0.36 \\
DigCreator2 & 2.85 & 5.53 & -0.13 & -0.18 \\
DigCreator3 & 1.78 & 5.33 & -1.20 & -0.38 \\
DigCreator4 & 2.98 & 5.58 & 0.00 & -0.13 \\
DigCreator5 & 1.97 & 5.50 & -1.01 & -0.21 \\
DigCreator6 & 3.98 & 5.92 & 1.00 & 0.21 \\
DigCreator7 & 3.47 & 6.29 & 0.49 & 0.58 \\
DigCreator8 & 3.86 & 6.18 & 0.88 & 0.47 \\
\hline$\sum$ & 23.80 & 45.68 & -0.04 & 0.00 \\
Average value & 2.98 & 5.71 & & \\
\hline
\end{tabular}

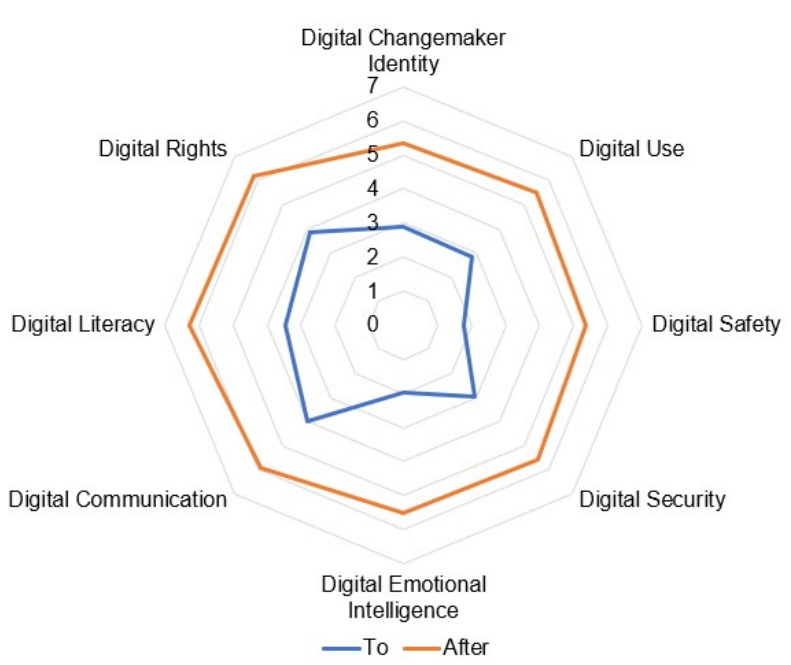

Figure 3. Graphical interpretation of digital intelligence skills at the level of "Digital Creator"

Assessment of digital intelligence skills at the level of "Digital Entrepreneur" is presented in table 3.

The estimated t-criterion is 7.22 and exceeds the $t_{\text {critical }}$, we can reject the null hypothesis and conclude that the difference in average values before and after the experiment is statistically significant ( $p=0.05)$.

As can be seen from table 3, students have increased the level of skills "Digital Entrepreneur" as a result of internships by an average of $23.6 \%$. Graphical interpretation of the results of the experiment for the level of "Digital Entrepreneur" are given in figure 4.

In the results of the experiment in the first, second and third stages, presented in figures 2-4, and in tables 1-3, we observe the heterogeneity of the indicators of the formation of digital intelligence skills for different components. After the first stage, the highest level is observed for the components of digital identity, security, emotional intelligence, and digital literacy, which we explain by additional thematic MOOCs and by the using of appropriately selected resources and services for training skills, matched the specified digital intelligence components. For the development of other digital intelligence components for the
Table 3. Assessment of digital intelligence skills at the level of "Digital Entrepreneur"

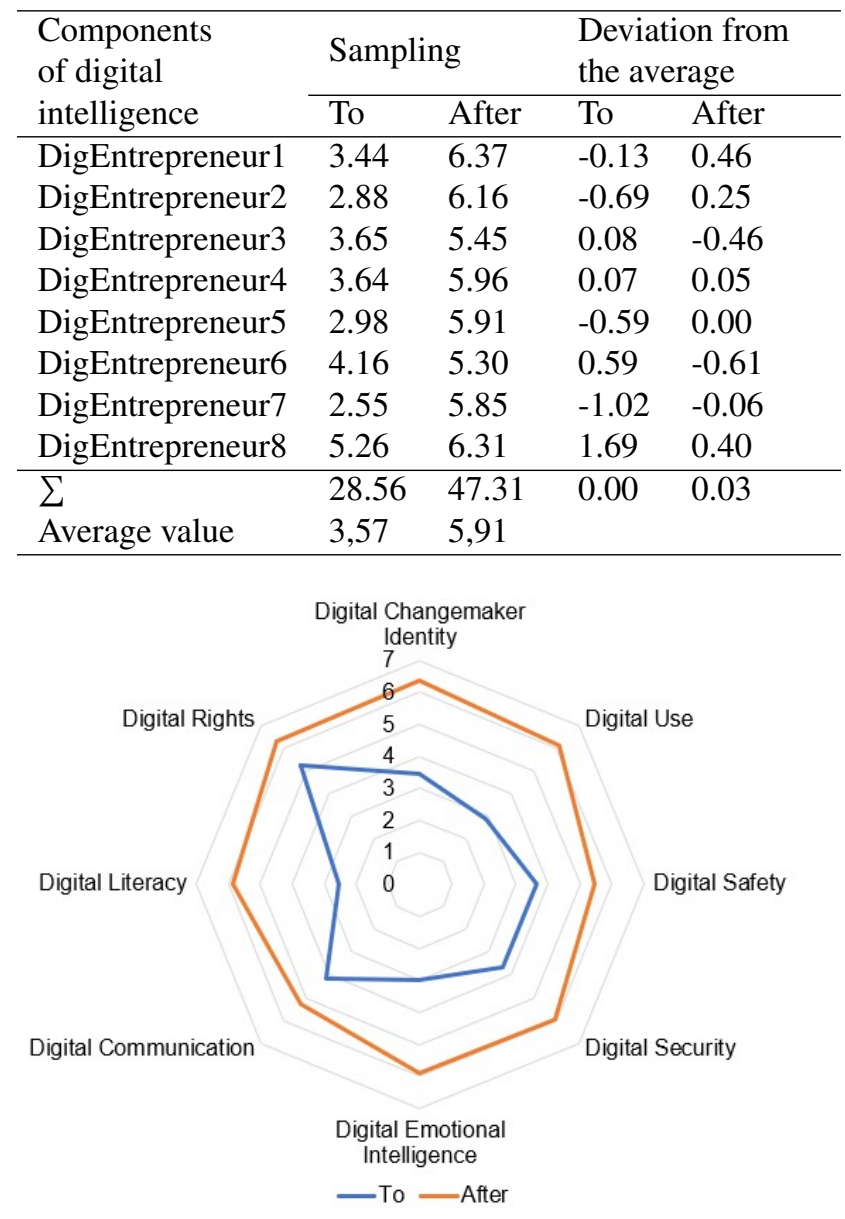

Figure 4. Graphical interpretation of the results for the level of "Digital Entrepreneur"

level of Citizen, other professionally-oriented courses are provided, during which these skills will be developed, for example, the discipline "DBMS". For the levels Creator and Entrepreneur levels, the level of skills formation with different elements is connatural, which is explained by the formation of competency and practice-oriented tasks considering the development of all components of digital intelligence, applying blended learning technology, which included project work methods, case method, individual and teamwork. Achieving the maximum values of the corresponding indicators of the digital intelligence is expected during the study of other professionally-oriented disciplines.

\section{Conclusions}

The analytical study made it possible to identify and describe the following components of the digital intelligence of the economist: Digital Changemaker Identity, Digital Use, Digital Safety, Digital Security, Digital Emotional Intelligence, Digital Communication, Digital Literacy, Digital Rights. The content of the Information Systems and Technologies academic discipline for training 
future economists at universities, in which digital intelligence skills can be developed, is proposed.

The developed approach gives the possibility to formulate digital intelligence skills of the Digital Citizen, Digital Creator and Digital Entrepreneur levels. The essence of the approach lies in the step-by-step formation of skills that correspond to each successive level. The initial stage involves studying the educational material and performing a series of hands-on classes within the disciplines. In this way, Digital Citizen skills can be formed. The second stage is to carry out a project work that requires creativity to solve the project task, and as a result, future economists will develop the skills of the Digital Creator level. The third stage involves the fulfillment of a real production situation, which requires the student not only to have previously acquired knowledge, skills and their application in practice, but also to gain new experience in solving typical production situations and responding to appropriate challenges. This stage is designed to build students' Digital Entrepreneur skills.

Three-stage approach of forming skills of digital intelligence was tested for three years to train students in "Economics". As a result of pedagogical experiment, the level of digital intelligence skills has been increased, in particular, the level of "Digital Citizen" increases by 22.8\%, the level of "Digital Creator" by $27.3 \%$ and the level of "Digital Entrepreneur" by $23.6 \%$. The obtained results show that under the given conditions of the organization of training during studying of educational course Information Systems and Technology in Economics at students of economic specialties the level of digital intelligence increases on the average by $24.4 \%$. But the development of digital intelligence of future economists is carried out in the future during the study of vocational courses, internships, diploma design, as well as through non-formal education.

Among the perspective areas of research, we see the definition of conditions and construction of models of individual educational trajectory for students of economic specialties in order to effectively develop their digital intelligence.

\section{References}

[1] K. Stopar, T. Bartol, Scientometrics 118, 479 (2018)

[2] E. Hazar, International Online Journal of Education and Teaching 5, 443 (2018)

[3] Y. Park, 8 digital skills we must teach our children (2016), https: //www. weforum.org/agenda/2016/06/ 8-digital-skills-we-must-teach-our-children/

[4] M.K. Kineshanko, K. Jugdev, in On the Line (Springer International Publishing, 2017), pp. 111125

[5] J. Škoda, L. Luić, Creating transmedia narratives to enhance digital intelligence in high school students, in ICERI2019 Proceedings (IATED, 2019), 12th annual International Conference of Education, Research and Innovation, pp. 9864-9872, ISBN 97884-09-14755-7, ISSN 2340-1095, http://dx . doi . org/10.21125/iceri.2019.2413
[6] J. Dostál, X. Wang, W. Steingartner, P. Nuangchalerm, Digital intelligence - new concept in context of future of school education, in ICERI2017 Proceedings (IATED, 2017), 10th annual International Conference of Education, Research and Innovation, pp. 3706-3712, ISBN 978-84-697-6957-7, ISSN 2340-1095, http: //dx.doi.org/10.21125/iceri.2017.0997

[7] D.M. Cismaru, P. Gazzola, R.S. Ciochina, C. Leovaridis, Kybernetes 47, 1924 (2018)

[8] M. Plachkinova, T. Pittz, Entrepreneurship Education and Pedagogy (2020)

[9] O. Kuzminska, M. Mazorchuk, N. Morze, V. Pavlenko, A. Prokhorov, CEUR Workshop Proceedings 2104, 366 (2018)

[10] O. Kravchenko, M. Leshchenko, D. Marushchak, Y. Vdovychenko, CEUR Workshop Proceedings 2422, 434 (2019)

[11] M. Ivanov, S. Ivanov, N. Terentieva, V. Maltiz, J. Kalyuzhnaya, E3S Web of Conferences 166, 13010 (2020)

[12] $D Q$ is the capacity to be aware of, participate and contribute in the digital economy for professional and personal reasons (ScooNews, 2017)

[13] DQ Global Standards Report 2019. Common Framework for Digital Literacy, Skills and Readiness (2019), https://www.dqinstitute.org/ dq-framework

[14] Tech. rep., Centre for the New Economy and Society (2018), http://www3. weforum.org/docs/ WEF_Future_of_Jobs_2018.pdf

[15] M. Christina, M. Liana, Polish Journal of Management Studies 10, 161 (2014)

[16] A. Ghafar, International Journal of Higher Education 9, 218 (2020)

[17] W.P. Wong, V. Veneziano, I. Mahmud, Information Development 32, 1027 (2016)

[18] W. Imbiri, International Journal of Emerging Technologies in Learning (iJET) 14, 71 (2019)

[19] T. Chen, G. Zhou, International Journal of Emerging Technologies in Learning (iJET) 8, 43 (2013)

[20] M. Shraideh, C. Drieschner, B. Betzwieser, H. Kienegger, M. Utesch, H. Krcmar, Using a project-based learning approach for teaching emerging technologies: An example of a practical course for introducing SAP Leonardo and SAP HANA, in 2018 IEEE Global Engineering Education Conference (EDUCON) (IEEE, 2018), ISBN 9781538629574

[21] M. Stoll (Springer-Verlag GmbH, 2014), chap. From Information Security Management to EnterpriseRisk Management, pp. 9-17, Innovations and Advances in Computing, Informatics, Systems Sciences, Networking and Engineering edn., https://www.ebook.de/de/product/ 23510245/innovations_and_advances_in_ computing_informatics_systems_sciences_ networking_and_engineering.html 
[22] Y. Raanan, Sinergie 78, 43 (2009)

[23] M. Dodel, G. Mesch, Information, Communication \& Society 21, 712 (2018)

[24] J. Burkell, A. Fortier, L. Valentino, S. Roberts, Tech. rep., Social Sciences and Humanities Research Council of Canada, Property London, Ontario (2015)

[25] S. Bonesso, E. Bruni, F. Gerli (Palgrave Pivot, Cham, 2020), chap. Emotional and Social Intelligence Competencies in the Digital Era, pp. 41-62, Behavioral Competencies of Digital Professionals edn.

[26] M. Hendon, L. Powell, H. Wimmer, Computers in Human Behavior 71, 165 (2017)

[27] I. Domazet, M. Lazić, in XXII International Scientific Conference Strategic Management and Decision Support Systems in Strategic Management: proceedings (Subotica, 2017)

[28] V. Gekara, D. Snell, A. Molla, S. Karanasios, A. Thomas, Skilling the Australian workforce for the digital economy (National Centre for Vocational Education Research (Australia) (NCVER, Adelaide,
2019), ISBN 978-1-925717-30-3

[29] M.J. O'Brien, K. Freund, International Journal of Education and Development using ICT 14, 4 (2018)

[30] L. Pangrazio, Discourse: Studies in the Cultural Politics of Education 37, 163 (2014)

[31] A.I. Santos, S. Serpa, International Journal of Social Science Studies 5, 90 (2017)

[32] M. Spante, S.S. Hashemi, M. Lundin, A. Algers, Cogent Education 5, 1519143 (2018)

[33] M.C. Murray, J. Pérez, Issues in Informing Science and Information Technology 11, 085 (2014)

[34] B.S.K. Chan, D. Churchill, T.K.F. Chiu, Journal of International Education Research (JIER) 13, 1 (2017)

[35] J. Palfrey, U. Gasser, M. Simun, R.F. Barnes, International Journal of Learning and Media 1, 79 (2009)

[36] P. Djekic, C. Loebbecke, Software Piracy Prevention through Digital Rights Management Systems, in Seventh IEEE International Conference on E-Commerce Technology (CEC'05) (IEEE, 2005) 